\title{
Collective Agents and Communicative Theories of Punishment
}

\author{
Bill Wringe
}

\section{Introduction}

In recent years, a number of theorists of punishment have been attracted to accounts of punishment which stress the idea that punishment has an important expressive or communicative dimension. ${ }^{1}$ At the heart of the communicative view is the idea that it is part of the function of punishment to communicate a message either to the offender, or perhaps to the society at large, and that the justification of punishment depends in an important way upon these ends. Communicative theories that emphasize the idea of communication with an offender are particularly attractive. They are often thought to represent an advance on more traditional forms of retributivism, ${ }^{2}$ insofar as they give an account on which it is possible to see why giving people the treatment they deserve might be a positive good. They also seem preferable to many consequentialist views on which the beneficial effects of punishment appear to be secured in ways that involve impermissibly treating offenders as a means to an end. ${ }^{3}$

Communicative theories are not without critics. ${ }^{4}$ Those critics have, for the most part, focused on questions about whether the communicative theorist can really succeed in justifying inflicting the sorts of treatment that we typically associate with punishment on individual offenders. Although these criticisms are interesting, and ought to stimulate advocates of communicative theories to consider carefully how they formulate their views, I believe that most of them can be met by sophisticated formulations of the communicative view. The problem that I wish to raise is different: it concerns the scope of the communicative view. In particular, I shall be concerned with whether the communicative view can allow for the possibility of punishing all of the kinds of offenders that one might want to regard as potential subjects of punishment. In particular, I shall be concerned with the question of whether the communicative view can give a plausible account of the punishment of collective bodies. The kinds of collective bodies which I have in mind include, primarily, business corporations, which are treated as potential subjects of punishment under many jurisdictions; and secondarily, nations, which might plausibly be regarded as potential subjects of punishment under actual or possible systems of international law.

I shall not defend in detail the claim that collective entities can, on occasion, be the appropriate subjects of punishment. For my purposes, it is enough to note that, in many jurisdictions, such entities are so treated..$^{5}$ It is a point against the

JOURNAL of SOCIAL PHILOSOPHY, Vol. 43 No. 4, Winter 2012, 436-456.

(C) 2012 Wiley Periodicals, Inc. 
versions of the communicative view that I shall be discussing that they would require substantial revision of our practices in these respects where other views would not. Advocates of those views might respond by arguing for a revisionary attitude to those practices. However, in doing so, they incur at least one of two possible costs: that of proposing and advocating workable alternatives to existing practices, or that of divorcing theories of punishment from application to some of the forms of punishment that we see in practice in actual working legal systems.

My discussion will focus primarily on the version of the communicative account of punishment put forward by Anthony Duff. Duff's work represents what is widely acknowledged, even by critics of communicative views, to be the best worked out and most sophisticated version of the communicative view, and thus the one that is most likely to be able to meet the criticisms that communicative views typically receive. ${ }^{6}$ I shall argue that Duff's account cannot be adapted to cover the punishment of the sorts of collective agents which I shall be discussing, and I shall put forward an alternative account, which still falls within the broad framework of expressive theories of punishment, which can. The points that I make should be of interest to anyone who thinks that the expressive function of punishment plays a role in its justification: anyone who adopts this view should have something to say about the punishment of collectives.

\section{Communicative Theories of Punishment and Corporate Bodies: Two Problems}

According to Anthony Duff's communicative theory of punishment, the justification of the harsh treatment that punishment involves depends essentially on the idea that punishment has a communicative function, and more particularly on the details of the communicative function that it is supposed to have. ${ }^{7}$ Duff takes punishment to involve harsh treatment directed at a member of a particular community, with the goal of communicating societal disapproval of their norminfringing behavior, to the end of inducing remorse or regret for that behavior. ${ }^{8}$ (While Duff does not make this explicit, it is plausible that such a justification only has any chance of succeeding in cases where the punishing institution can legitimately be regarded as "speaking for" the community whose norms have been infringed. $)^{9}$

Duff's theory is attractive for at least two reasons. First, it explains, as many versions of retributivism seem unable to, why we should regard an institution that has, as a central part of its purpose the infliction of suffering as having any value. Where the punishment of individuals is concerned, Duff's answer to this question depends on the fact that the individual who is subject to the harsh treatment that constitutes punishment is a member of a community, and that regret or remorse at wrongdoing plays an important role in enabling individuals who are punished to become reintegrated with their community. Second, its focus on the idea of communication enables us to see that an acceptable theory of punishment needs 
to treat the punished individual as an agent whose capacity to respond to the treatment meted out to them by the punishing institution is central to the moral acceptability of punishment, while insisting that it is their status as a wrongdoer that makes them liable to such treatment. ${ }^{10}$ It thereby provides some grounds on which we might resist the claims of the so-called victim-centered theories that accounts which focus on the rehabilitation of perpetrators of criminal acts-as the communicative account might be seen as doing - treat them too well.

Nevertheless, it is not clear that Duff's account can be fully general. For not all of the agents on whom we take it to be appropriate to inflict legal punishment are individuals. Two obvious counterexamples are corporations and nations. Under many jurisdictions, corporations, and not simply the individuals who make them up or who act on their behalf, can be prosecuted for criminal activity. ${ }^{11}$ It is not immediately obvious how a communicative theory of punishment might be extended to cover the case of punishments inflicted on collective entities of this sort. Indeed, there are two problems that need to be faced. One arises from the fact that, on Duff's view, punishment should be aimed at inducing regret or remorse. The second is that for the account to succeed in providing a justification of punishment, we must have some reasons for finding the remorse or regret that the punished individual experiences as having some kind of value. Call these two problems the "intelligibility of collective regret and remorse problem," and the "value of collective regret and remorse problem," or the "intelligibility problem" and "value problem," respectively. I shall argue that, although the intelligibility problem can be solved, the value problem cannot. These arguments will be the focus of sections IV and V, respectively.

One might conclude from this that we should discard the communicative view. However, I shall argue that we should adopt a view on which the punishment of collective bodies is justified by reference to its communicative effects on a wider audience. In other words, we should adopt a "denunciatory" account of the punishment of corporate bodies. Views of this sort do not face the problems that a direct application of Duff's view to the case of corporate bodies would face. There is no analogue of the intelligibility problem for such accounts (since they do not entail that corporate agents need to be capable of having emotions), and as I suggest - albeit briefly_in section VI, the closest analogue of the "value problem" is relatively easy to solve. I also argue (in sections VII-XI) that what some have seen as the biggest obstacle to accepting denunciatory theories of punishment-—namely that they appear to involve treating individuals as means to an end-is not a problem when we consider the possibility of a denunciatory account of the punishment of collective entities.

\section{Evasive Responses}

In what follows, I shall ignore what one might call "evasive" responses to the problems I have identified for Duff's view. ${ }^{12}$ By an "evasive" response I mean one 
that attempts to deal with the issues I have identified without drawing on the resources of the communicative theory itself; for example, by suggesting that what is involved in the punishment of corporate entities should not be regarded as punishment, correctly so-called, or that we should not think of justifying it in the same way as we justify the punishment of individuals, or simply that corporations should not be punished. One reason for ignoring these responses is that they tell us very little about how the communicative theory might contribute to our understanding of punishment in the corporate case. ${ }^{13}$

Evasive responses might be motivated in a number of non-ad hoc ways. If there are no collective entities, then the talk of punishing them should either be eliminated or not be taken literally. However, eliminativism about collectives is not the only way in which an evasive response might be motivated. Someone who holds that collective bodies exist, but that they cannot be agents, has reason to adopt an evasive response. So does someone who thinks that criminal activity requires the formation of intentions (because crimes involve a mens rea) and that collective bodies do not have intentions. ${ }^{14}$

None of these views about collectives and collective agents seem to be sustainable. ${ }^{15}$ The most plausible of them is the third. However, even the third does not make the case for an evasive response unanswerable. For even if we think that the idea of a collective intention is unintelligible, we still need to reckon with the possibility of punishment for offenses involving strict liability, to which concerns about intention are irrelevant. ${ }^{16}$ Furthermore, evasive responses are not cost-free. Someone who wishes to adopt one needs to explain both why we speak of punishment in both the individual and the collective case, and also provide some account of how punishment might be justified in the corporate case. Taken together, these points suggest that there might be some value in exploring a non-evasive response. $^{17}$

\section{Collective Emotions}

One might think that non-evasive responses are ruled out on the grounds that they would require corporate bodies to be subjects to emotions such as regret and remorse, and that this is impossible. This objection can be met.

Someone who regards corporate bodies as possible objects of punishment is likely to have to regard such bodies as collective agents. Talk of collective agents may bring in its wake talk of collective beliefs and desires. Still, there seems to be a large gap between regarding collective bodies as agents and regarding them as subjects of experience. One might hold that if we want to attribute emotions such as regret and remorse to collective bodies, we must regard them as subjects of experience and not just as agents, and that although they can be the latter, they cannot be the former.

This objection might be thought to arise from a commitment to a mistaken model of emotion. Someone who accepts a "judgmentalist" theory of emotion—of 
the sort put forward by Martha Nussbaum ${ }^{18}$-might reject the idea that it makes sense to think of collective bodies as being capable of having beliefs or desires but not as being subject to guilt or remorse. For if emotions involve a complex range of judgments, but no non-judgmental elements, there need be no obvious logical bar to thinking of collective bodies as subjects of emotions.

Many philosophers of emotion think that Nussbaum's judgmentalist account gives an inadequate account of emotional experience. ${ }^{19}$ I disagree. However, even if we accept Nussbaum's account, the possibility of collective emotions does not follow straightforwardly from the possibility of collective beliefs and judgments. In order to account for the phenomenology of many emotional states, Nussbaum appeals to features of the functional role of certain types of judgment-features relating to their "freshness" and to their centrality to the identity of a subject. It is not clear that these can be replicated by any form of collective judgment.

The communicative theorist might instead suggest that we think of punishment as being aimed at inducing remorse in individuals who act on behalf of a corporate body, rather than in the corporate body itself. This response is unsatisfactory: it overlooks the fact that artificial persons can continue in existence while those who act on their behalf change. If the punishment of artificial persons was aimed at inducing remorse in the individuals who make up a corporate body, then in cases like this, it would be unjust: it would involve inflicting suffering on individuals who had not done anything to deserve it.

One might respond to this argument by suggesting that in cases where the membership of a collective body changes, it should be exempt from punishment. However, this suggestion seems like a bad one: it would make it possible for corporations to avoid punishment too easily, since they could easily vote someone new on to the board, and it would appear to rule out the possibility of nations being punished at all, since their membership changes almost every second. One might also respond by arguing that there is a logical bar to an individual's feeling of remorse for acts committed by a collective body before they were a member of it or in a position to act on behalf of it. However, there seems to be little reason to think that such a logical bar exists. ${ }^{20}$ Whether or not it is psychologically possible for an individual to feel remorse in a case like this will depend, in any given case, on the makeup of the individual, and in particular how strongly they identify with the collective body of which they are a part. ${ }^{21}$

Margaret Gilbert makes a more promising suggestion. ${ }^{22}$ Gilbert holds that groups can be the subjects of collective emotions, including the emotion of remorse. Collective emotions of this sort require group members to have what she calls a "joint commitment" to a particular emotional response on the part of the collective that they make up.

A group $\mathrm{G}$ feels remorse over an act $\mathrm{A}$ if and only if the members of $\mathrm{A}$ are committed to feeling remorse as a body over A. (Gilbert 2001, 229)

Gilbert does not gloss the phrase "feeling remorse as a body" directly. However, she holds that a joint commitment to feeling remorse "as a body" need 
not entail a commitment on the part of each individual in the group to feeling remorse on their own behalf.

I might be able correctly to avow "we feel remorse over our act" without being able correctly to avow "I feel remorse over our act" (ibid.).

Gilbert does tell us what it is for a group to accept a goal as a body:

For two [or more-my addition] people to accept a goal as a body is for them as far as is possible to constitute through their several actions a single "body" or person who accepts that goal. (Ibid., italics in original)

However, it is not clear how much this helps. Even if it is possible for a group of individuals to act together in such a way as to constitute a body trying to achieve a certain goal, one might think that it is not possible for them to constitute a body that feels a certain way, on the grounds that only subjects of experience can have feelings and that collective bodies are not subjects of experience.

However, even if collective bodies are not centers of experience in their own right, they can act in ways that correspond to the behavioral expressions of emotion. There are logical ties between remorse and its expression, and between sincere regret and the desire to make amends where appropriate. Where collective bodies have acted wrongly, they can act collectively in ways that, if performed by an individual in response to individual wrongdoing, would constitute expressions of these emotions. For example, the official spokesperson for a group can express regret for wrongdoing on behalf of a collective; collective bodies can look for and find ways of proceeding that prevent similar wrongs from happening in the future, and they can act in ways that compensate those who have been harmed. We might see actions of this sort as behavioral analogues of remorse and regret, and a joint commitment to acting in these sorts of ways might be taken to constitute a joint commitment to feeling remorse as a body, ${ }^{23}$ or alternatively as an appropriate substitute for it in the collective case. ${ }^{24}$ If so, then the fact that collectives are not subjects of experience need not present an insuperable problem to the advocate of the communicative view.

One might object that collective remorse, if conceived of in this way, seems like the remorse of an insincere individual, and the communicative theorist cannot give us any reason for valuing insincere remorse. ${ }^{25}$ The objection fails: even if it is true that the communicative theorist should only care about sincere remorse, this presents no obstacle to the communicatively justified punishment of collectives. We can distinguish between sincere and insincere remorse in the case of collectives, just as we can in the case of individuals. Remorse is insincere if there is a mismatch between its verbal expressions and other typical behavioral expression, such as attempts at reform. A collective's expressions of remorse may be insincere when not backed up by attempts to make amends where possible, just as an individual's can. They can also be sincere when they are so backed up. (In the case of an individual, the reasons for which they are acting are relevant to 
whether their expression of a given emotion is sincere. The same will often be true where corporations are concerned. ${ }^{26}$ But the reasons for which corporations are acting are often best judged by reference to their behavior.)

\section{The Value of Collective Remorse}

Even if it makes sense to talk of collective emotions, non-evasive responses on the part of the communicative theorist face another problem. It is not clear that we should value remorse on the part of collective wrongdoers in the same way as we value the remorse of individual wrongdoers.

The justification of punishment that the communicative theorist puts forward can only function as a justification if one thinks that there is something good about agents who have committed crimes experiencing remorse or regret. As far as the punishment of individuals is concerned, there seems little difficulty here. For one might take this regret or remorse to be good in a number of ways. One might, for example, take it to be non-instrumentally valuable for individuals to have a proper appreciation of the moral quality of their action. Or one might think that this appreciation was a necessary part of the individual in question either having, or deserving, full moral standing in the community of which they are a member. Or, on a more mundane level, one might think that the experience of regret and/ or remorse might have an effect on the character of an individual that would make them less likely to offend in the future. Or one might appeal to a combination of all of these factors.

It is much harder to see how or why the behavioral analogue of regret or remorse in a collective body should be valuable. Even someone who is relaxed about allowing collectives into their metaphysics might well balk at regarding the mental states of collective entities as non-instrumentally valuable. And it is not clear whether we should see collectives as being part of our community in the way in which the individuals who make up that community presumably are.

One possibility to consider is that inducing the behavioral analogue of remorse in collective criminals might be good for at least some of the surviving victims of crimes, or for those who, while not being direct victims, have been harmed by the commission of the crimes. It certainly seems plausible that expressions of remorse by collective bodies that have harmed individuals might be of benefit to victims in some cases. For example, one might think that it is appropriate for the government of the United States to express regret or remorse over laws permitting slavery and racial segregation, and one reason for thinking that this is appropriate might be that some form of limited acknowledgment of ways in which these laws have contributed to ongoing harms that have affected Black citizens of the United States up until the present day would be of some symbolic benefit to those who suffer those harms. ${ }^{27}$

However, this point is unlikely to contribute much to a defense of a communicative theory of punishment applied to collective bodies for two reasons. First, many corporate crimes involve inchoate offenses, such as recklessness. ${ }^{28}$ Offenses 
of this sort often do not involve particularized harms to specifiable individuals. So a defense of the punishment of collectives that relies on the value of expressions of remorse and regret to such individuals is unlikely to cover all the kinds of cases where we might think that it is appropriate to punish collective entities. A second point is that in cases where expressions of remorse might be of value to victims, a significant part of whatever value they might have seems to be dependent on their being, and being seen as freely given rather than coerced. ${ }^{29}$

One further possibility to consider is that collectives that act in ways that manifest the behavioral analogues of remorse and regret might be less likely to infringe the norms that had led to them being punished in the first place than they might be if they were not so punished. It is not clear whether this is true: it certainly seems open to doubt. Even if it were not, one might think that the advocate of the communicative view should be embarrassed by needing to rely on this point. For it seems to involve thinking that the purpose of punishing collective entities is simply to reduce the rate of corporate crime. But if one does think this, then it is hard to see why one should prefer a way of doing this, which operates via the agency of particular corporate bodies to one that works through a wider variety of agencies, as, for example, a deterrent-based account might. If so, the communicative account seems otiose.

\section{From Communication to Denunciation}

One might conclude from this that the notion of communication has no significant role to play in an account of the punishment of collective bodies. However, I think that this would be a mistake. One reason for thinking so goes back to Joel Feinberg's essay "The Expressive Theory of Punishment." ${ }^{30}$ In that essay, Feinberg argued that we could only distinguish between punishment, properly so-called, and some form of tax on undesirable behavior by seeing punishment as having an expressive function.

Some might hold that where corporate bodies are concerned, there is no real need to make a conceptual distinction between punishment and taxation. A response of this sort is, in effect, an evasive response of the sort that I discuss, and dismiss, in section II. Whether or not the reasons I give for doing so seem compelling, it is worth noticing that another response is possible.

The response would involve agreeing with Feinberg and Duff that punishment, properly so-called-including the punishment of collective entities-involves communication of some sort, but disagreeing with them about the intended audience of the communication. It would involve, that is, what is sometimes called a "denunciatory" as opposed to a "communicative" account of punishment. ${ }^{31}$ On a denunciatory account, the intended audience of the message that punishment is supposed to communicate is not, as on Duff's account, the perpetrator, but the society whose norms have been transgressed. The content of the message would be that the society has certain norms and takes them seriously. 
I shall not attempt a full-scale defense of a denunciatory account of the punishment of corporations. Any such account would need to show that the sorts of denunciatory communication that played a role in the justification of the punishment of corporations was in some way beneficial to a wider society, and that the benefits were commensurate with the costs involved in bringing corporations to trial and in imposing such punishments on them. This would, in part, involve empirical claims whose defense is beyond the scope of this paper. ${ }^{32}$

However, it is worth both noticing the initial plausibility of the claim that denunciatory communication of this sort might serve a valuable and social role, and also drawing attention to the fact that there is a range of benefits that one might appeal to in this context. In some of them, the role of the denunciation might be purely instrumental: for example, it might turn out that denunciation via punishment led to better corporate compliance. But other benefits might be less easily conceived of in ways that make them independent of the denunciatory message. ${ }^{33}$ For example, one might think that citizens are benefited directly by living in a society, which makes clear that collectives are just as subject to legal and moral assessment as individuals. This might, for example, contribute to a liberal society's goal of showing respect for the agency of its citizens, or of demonstrating a commitment to treating those with and those without powerful associates as equals.

One important objection to denunciatory accounts of the punishment of individuals is that such an account appears to involve treating the punished individual merely as a means to an end: in this case, the end of a society communicating its norms to its members. ${ }^{34}$ Whether or not this criticism of denunciatory accounts of the punishment of individuals is correct, it is less obvious that a similar objection can be raised against a denunciatory account of the punishment of corporate bodies. There is no plausible general moral prohibition on treating such bodies as a mere means. Indeed, one might think it was strange to treat them as anything else.

Still, even if there is no general prohibition on treating collective bodies as a means to an end, one might think that there are prohibitions on treating certain kinds of agent as a means, which could be a significant objection to a denunciatory account. I shall consider two slightly different objections along these lines. The first is that treating corporations as a mere means might necessarily involve treating individuals as a mere means, and this would be objectionable. ${ }^{35}$ The second is that while the scope on the prohibition of treating agents as mere means does not necessarily include within its scope every collective agent, it does include all collective agents who are capable of remorse. ${ }^{36}$

\section{What Is It to Treat an Agent as a Means?}

The idea that treating a collective agent as a means involves treating the individuals who make it up as a means is based on two straightforward thoughts. The first is, of course, that collectives are made up of individuals. The second is 
that there is no way of inflicting suffering on collectives without imposing suffering on those individuals. The idea that treating a collective as a mere means involves treating the members of it as a means cannot simply follow from the fact that the collective is made up of individuals. If you treat me as a mere means to an end-for example, by spreading malicious gossip about me simply for your own amusement-you do not thereby treat my arms, legs, and torso as a means to an end (unless, perhaps, the malicious gossip focuses on some aspect of my physical appearance). One might say that this is simply because my arms, legs, and torso are not themselves agents. This point is significant, but not decisive. It is significant, because in order for you to treat me as a mere means in a way that is morally objectionable, I must be the right kind of agent (and a fortiori I must be some kind of agent). But it is not decisive. In order to treat me as a mere means, you must stand in the right sort of relationship - or perhaps we should say the wrong sort of relationship - to my agency. And, I shall claim, you do not stand in that sort of relationship to my agency, just because you stand in that sort of relation to the agency of some collective of which I am a part.

In order to evaluate this claim, we need to look more closely at the question of how one agent needs to stand in relation to the agency of another in order to treat them as a mere means. As Duff points out, the precise import of this Kantian language is far from clear. ${ }^{37}$ There are at least three ways in which the prohibition might be understood.

First, one might take it that an individual is treated as a mere means if they are treated in ways in which they have not actually consented to. However, it would be unreasonable for someone who accepts Duff's communicative account of the punishment of individuals to object to the denunciatory account I have put forward here that it involves treating individuals as mere means on this understanding of the phrase. For Duff's communicative account also allows that individuals may justly be punished even though they have not actually consented to the harsh treatment that is inflicted on them.

Indeed, it is arguable that on this account, there are no accounts of punishment that do not involve treating someone as a means, since it is not clear that any available account takes punishment only to be justified in case where individuals actually consent to it. ${ }^{38}$ To put matters differently, if there is a prohibition on treating individuals in ways that they have not actually consented to, this constitutes an objection to punishment in any of the forms that it is currently conceived of, and not simply to the denunciatory account of the justification of punishment of collective agents, which I am advocating here. ${ }^{39}$

For this reason, I shall ignore this way of understanding the prohibition on treating individuals as mere means, and concentrate on two others. One is based on Duff's own interpretation of what the Kantian prohibition amounts to. He suggests that the Kantian prohibition on treating individuals as means should be equated with a requirement to treat individuals as persons or as responsible agents. ${ }^{40}$ The other interpretation of the prohibition on treating individuals as a mere means to an end can be found in Onora O'Neill's interpretation of Kant's 
moral philosophy. On O'Neill's account, an agent treats a second agent as a mere means when the first agent has, as the maxim of their action, something to which the second agent could not consent. ${ }^{41}$ I shall argue that on either of these accounts, one can treat a collective body as a mere means to an end without so treating the individuals who make up that collective body.

\section{Clarifying the Objection}

Before doing so, however, it will be helpful to say more about what, exactly, those who think denunciatory punishments of individuals treat individuals as means to an end are objecting to.

Call the practice of making a public expression of disapproval of a person's wrongful behavior without necessarily inflicting harsh treatment on them "simple denunciation." One might argue that one could not engage in an act of simple denunciation against a corporate body without simply denouncing at least some members of the corporation-namely those who bore some responsibility for the behavior of the corporation. If simple denunciation of an individual involved treating the simply denounced individual as a mere means, then it would follow that the practice of simply denouncing corporations involved wrongly treating individuals as means to an end.

However, it would be hard to sustain the claim that simple denunciation necessarily involves wrongly treating someone as a means to an end. Indeed, on two of the accounts of what is involved in treating individuals as a means to an end, it is clear that at least some cases of simple denunciation do not count as treating them as a means to an end. On Duff's account, treating someone as a means to an end is regarded as being the antithesis of treating them as a person or responsible agent. However, it is surely possible to imagine cases of simple denunciation that have, as part of their point, to draw attention to the very fact that an individual is a responsible individual. The same is true on O'Neill's account of what it is to treat someone as a means to an end: there is no reason why the simple denunciation of an individual must involve treating them in a way that they could not consent to.

Those who object to denunciatory forms of punishment on the grounds that they involve wrongly treating people as a means to an end are not objecting to simple denunciation. They are objecting to the practice of inflicting harsh treatment on individuals for the purpose of expressing disapproval of their norm-infringing behavior. Call this "denunciatory punishment." The objection under consideration is that denunciatory punishment involves (or would involve) wrongly treating individuals as a means to an end, and not that simple denunciation does.

\section{Does Treating Collectives as a Mere Means Involve Treating Individual Members of the Collective as a Mere Means (I)?}

As we have seen, Duff holds that the prohibition on treating agents merely as a means is to be interpreted as a requirement that we see them as individuals who 
are responsible for their own behavior. It is not clear to me that, on this account of what it is to treat someone as a means, denunciatory punishments of agents need to involve treating those agents merely as a means to an end. Nor-as I have already observed - is it clear that there is anything wrong with treating collective bodies as a means to an end. (I shall discuss this further in section XI). Finally, it does not seem to be true that in treating collective bodies merely as a means, we would thereby be treating individual members of a collective merely as a means. For under certain circumstances we might think it appropriate not to treat a collective body as an agent that is responsible for its own actions, simply because those actions depended entirely on the actions of one particular individual (whom we might then hold responsible instead).

More importantly for present purposes, there is no obvious reason for thinking that if we inflict harsh treatment on a corporation, and this treatment has harmful effects on those who are associated with it, we necessarily fail to treat those individuals as persons or responsible agents.

Consider a situation where a large fine is imposed on a corporation. It is true that the imposition of the fine may result in harm to various individuals. Profits may be hit, harming shareholders; prices may go up, harming consumers; as market position is lost, workforces may be reduced, harming employees; managerial salaries may be reduced; and so on. However, there are two points to make about this. First, even in relatively straightforward cases in which individuals are punished for individual crimes (perhaps along the lines which the communicative theorist would be willing to sanction), inflicting harsh treatment on those individuals may result in harms to other individuals who have not committed the crime in question, such as family members. Although this might, in some cases, be regarded as a reason for mitigating an individual's sentence, we would not normally regard a failure to wholly remit the sentence imposed as involving the treatment of the criminal's family members as a means to an end. Second, in the corporate case, and particularly in cases where fines are imposed on corporations, there is a further reason for denying that any resulting harms involve the punishing authority treating affected individuals as a means to an end. For, in cases like this, the identities of the individuals affected and the exact nature of the harms that result will normally depend, to a large extent, on decisions made at the corporate level. This means that we have reasons for not regarding the harms that are inflicted as ways in which the punishing authority treats shareholders, consumers, workers, or managers. To see things in that manner would be to deny the agency of the corporate decision makers. A fortiori, they should not be seen as ways in which the punishing authority treats individuals as means to an end. ${ }^{42}$

\section{Does Treating Collectives as a Mere Means Involve Treating Individual Members of the Collective as a Mere Means (II)?}

I turn now to O'Neill's account of what it is for an agent to treat another agent as a means. It is worth noticing, as a preliminary matter, that on this 
account, it is far from obvious how many of the forms of punishment that an advocate of a denunciatory view of punishment might wish to see imposed on corporate bodies would actually involve treating those bodies as a means to an end. For example, it is not obvious that a corporation could not consent to a maxim according to which corporations that were found to have breached certain kinds of regulatory standards should be subjected to large fines. In fact, corporations might have good reasons for consenting to such maxims. For, if generally followed, such maxims might reduce the extent to which corporations with law-abiding decision makers were put at an unfavorable position vis-à-vis their competitors. (Furthermore, it seems plausible that if corporate bodies can consent to being treated in such ways, so can the individuals who make them up.)

Nevertheless, one might argue that if one understands the prohibition on treating agents as means to an end in the way that O'Neill suggests, some forms of punishment of which the denunciatory theorist might approve could involve treating collective bodies as means to an end. Consider, for example, what is sometimes known as the "corporate death penalty," where in response to particularly heinous forms of corporate wrongdoing, a corporation is actually dissolved. ${ }^{43}$ It might turn out that for certain formal reasons, a corporation could not consent to its own dissolution. ${ }^{44}$ There might also be formal reasons why a corporation might not be able to consent to measures that would reduce its profitability: for example, it might be constituted in such a way as to require it, as a matter of policy, to pursue policies that would maximize shareholder value. If it was true that, on O'Neill's account of treating an agent as a mere means, in treating a collective as a mere means to an end, one was thereby treating some or all of the members of the collective as mere means to an end, then it might follow that punishments of corporate bodies of this sort would involve treating individuals as mere means to ends.

However, on O'Neill's account, it is not true that in treating a collective as a mere means, one thereby treats the individuals who make it up as mere means. This is because it simply does not follow from the fact that a collective could not consent to the maxim of some agent's action that none of the individuals who make up the collective could consent to this. In fact, it is not clear to me that there is any reason why they could not all consent to it. This is because, on a plausible account of collective consent, a collective can consent to something without all its members consenting to it, and all the members of the collective can consent to something without the collective consenting to it.

Consider, for example, an account of collective consent modeled on Gilbert's work. Collective consent would involve a form of joint commitment on the part of some individuals, to consent as a body to certain treatment. The individuals might do so while being individually convinced that the treatment was inappropriate. Or, more relevantly for the current discussion, they might each individually be convinced that the treatment was appropriate, while being unable to express a collective commitment to that view. (They might, for example, each take themselves to be morally required - for example, by means of a previously given promise - to act in ways that served the interests of the other individual members 
of the collective body.) This means that it would be possible-at least in principle-for a collective to be treated in ways to which it was unable to consent without this entailing that the individuals in question were unable to consent to be treated in this way. In other words, it is possible for a collective to be treated as a mere means without any individual being treated as a mere means.

This argument establishes the possibility in principle of a collective body being treated as a mere means without any particular individual being treated as a mere means. But one might wonder about the implications of this claim for the forms of punishment of collective bodies, which I have suggested might involve treating those bodies as means to an end. Consider, once again, the possibility of a corporate body that is, for formal reasons, unable to consent to its own dissolution (perhaps because such a possibility is ruled out by its articles of association). It would not follow from this fact about the corporation that anyone involved in the corporation should be incapable of consenting to its being wound up. (One might think that in the normal course of things, those who stood to profit from the corporation's activities or those who were in leadership roles might be unwilling to consent, but this is not the point at issue, and is, in any case, not necessarily true: imagine a situation where, as a result of large-scale corporate wrongdoing, the board of directors of a corporation resigns and is replaced, pending judicial proceedings, by a caretaker board. Members of such a board might well be in a position to consent to the corporation in question being wound up.)

\section{Remorse and Respect}

I suggested earlier that there was no easily discernible reason to think that a moral requirement to treat individuals as responsible agents should bring with it a requirement to treat collective bodies as responsible agents. However, one might wonder whether, in conceding that corporations are capable of remorse, I have already conceded that they are deserving of the kind of respect that makes it impermissible to treat them as means to an end.

The suggestion here would be that a collective's being capable of remorse entails its seeing itself as a morally considerable agent, and that nothing —or at least very little-over and above being able to see oneself as a morally considerable agent is required for one to actually be an agent who cannot permissibly be treated as a means to an end This line of argument is certainly ingenious. The conclusion, however, seems extremely implausible. So my aim will be to show that we can reject the claim that collective agents cannot permissibly be treated as a means to an end without needing to deny that they are capable of remorse.

Since the argument under discussion is framed in Kantian terms, I shall use some Kantian terminology. Since it is possible that my understanding of this terminology is non-standard, I should emphasize that the main point at issue here is not whether my understanding of the terminology is authentically Kantian, but whether the arguments framed using the terminology are cogent. With that in 
mind, here are two points about terminology. First, I shall treat the phrase " $\mathrm{X}$ is worthy of moral respect" as being equivalent to "It is impermissible to treat X merely as a means to an end," and I shall assume that if it is impermissible to treat $\mathrm{X}$ merely as a means to an end (i.e., if $\mathrm{X}$ is worthy of moral respect), then $\mathrm{X}$ can have ends that give rise to duties in other agents, simply because they are ends that $\mathrm{X}$ has. I shall also talk, in a way that I take to be Kantian, of agents having some ends conditionally and other ends unconditionally, and I shall also assume, with Kant, that duties are unconditional ends.

According to the objection I am considering, a capacity for remorse entails, at the very least, a capacity to grasp that one is an agent, and that one is responsible, morally, for one's actions. This is certainly plausible in the case of an individual's remorse, and claiming that collective remorse is unlike individual remorse in this respect seems uncomfortably ad hoc. It also seems plausible that an agent that can see itself as being morally responsible for its actions should see itself as having duties. I suggest that an advocate of the view I am defending can, and should, accept all of these points.

The objection under consideration adds to these points the claims that an agent that can see itself as having duties should be seen by others as an agent that deserves respect. I claim that the objection fails because this claim is false. However, and as we shall see, it is false in a way that is easy to miss if we assume that the only agents we are considering are individual human agents.

There are two ways in which one might argue for the claim which I take to be false. On the first line, the reasoning would be that an agent that recognizes itself as having duties is one that must regard itself as deserving of respect, and an agent that recognizes itself as worthy of respect must be regarded as worthy of respect by others. On the second line, it would be that an agent that recognizes itself as having duties should be regarded as having duties by others, and that an agent that is regarded as having duties by others should be regarded as being worthy of moral respect from others. While both of these lines of argument seem promising, I think that neither of them establish the desired conclusion.

Consider the first. It is plausible that an individual who sees himself or herself as having duties does for that very reason have to see himself or herself as having ends that are-in Kantian language — unconditionally valid, or, in less Kantian language, as worthy of pursuit independently of any of the agent's desires. And one might think that the ends that are worthy of pursuit by an agent, independently of that agent's desires, give rise to reasons that ought to have weight for any agent. And to have ends that give rise to reasons that have weight for all agents is, one might think, to be deserving of respect. So there is something to the idea that an agent that sees itself as having duties must see itself as deserving of respect.

Does it follow that other agents should see such an agent as deserving of respect? If we restrict our attention to the case of individual agents, it might seem so. For one might think that we should, after all, see all other human beings as deserving of respect. But to say this is not to say that we should see other human beings as worthy of respect because they see themselves as being worthy of respect. 
And there is, even, a good reason not to make this latter claim, namely that it seems to hold out the possibility of giving a moral explanation of something for which there is no (further) moral explanation and where the demand for a moral explanation is inappropriate. Arguably, the fact that we should respect other individual moral agents is a brute moral fact, not a fact that needs to be explained by reference to other facts, and a fortiori not by the fact that they see themselves as being worthy of respect.

This point suggests that there is little reason to think that we can argue successfully that corporations should be seen as ends-in-themselves along the lines being considered here. In order to have such an argument, we would need to think that a claim that we are obliged to respect agents that respect themselves could justify a claim that we are obliged to respect particular moral agents. I have argued that a claim of the first sort cannot explain a claim of the second sort. I now suggest that if a claim of the first sort cannot explain a claim of the second sort, it cannot justify a claim of the second sort either. Any reason for doubting a claim of the second sort would be a reason, and indeed just as good a reason for doubting a claim of the first sort.

So while the first argument does not look absurd, it seems likely to be unsuccessful. What about the second? We need not give much attention to the claim that a being that can see itself as having duties should be seen by others as having duties. For the question of whether corporations should be seen as having moral duties is presumably not likely to be in dispute here. So everything depends on whether an agent that is seen as having duties should, for that reason, be seen as being worthy of respect. Here, I think that the answer is no, and that the reason why depends on the kinds of duties that corporations have.

If corporations have duties, they have ends that are unconditional. One might think that such unconditional ends would be binding on all moral agents, and that consequently their existence imposed duties on all moral agents. Suppose this is right. One might think that this meant that corporations were deserving of respect, because for a being to have ends that impose duties on all moral agents simply is for that being to deserve respect. But this is not correct. For a being to deserve respect is for it to have ends that impose moral duties on other agents simply because they are then ends of that agent. And corporations have no such ends. The unconditional ends that they have-and the duties that they thereby impose on other agents-involve duties that would fall on other agents in any case. So these ends do not impose moral duties on agents simply because they are ends of the corporate agent. If this is right, the second line of argument does not establish that corporations are deserving of moral respect. In other words, it does not establish that it is impermissible to treat corporations as means to an end.

\section{Conclusion: Evasiveness Reconsidered}

In section VI, I suggested that those who are attracted to Feinberg's view about the expressive nature of punishment properly so-called should adopt a 
denunciatory account of the punishment of corporations. In sections VII-XI, I considered objections to such an account, and rejected them. In the absence of other compelling objections, the denunciatory account seems to be a plausible account of the punishment of corporations. Those who are also prepared to accept a denunciatory account of the punishment of individuals are, therefore, in a position to adopt a straightforwardly univocal account of punishment.

What of those, like Duff, who accept Feinberg's point but think that a denunciatory account of the punishment of individuals is unacceptable? I have argued that they should not have similar objections to a denunciatory account of the punishment of corporations. But might they not reasonably suspect that an account of punishment on which the punishment of both individuals and corporate bodies has an expressive role, but on which the audience of the expressive communication differs in the two cases, commits them to a view on which the punishment of corporate bodies is not punishment properly so-called? Isn't this just another kind of evasive response of the sort discussed in section III? I do not think so. On the view under consideration, both cases are properly called punishment insofar as they both involve communication, even though the audience and point of the communication differ. This is not merely an arbitrary difference, as was the case with some of the evasive responses considered earlier, but one that appropriately reflects obvious and important differences in moral standing between individuals and corporations.

\section{Notes}

${ }^{1}$ See, for example, Duff (2001), Bennett 2008, Von Hirsch (1993), Hampton (1992). Many of these works acknowledge Feinberg (1970) as an important influence.

${ }^{2}$ Duff argues that his version of the communicative view is a form of retributivism. See Duff $(2001,31)$.

${ }^{3}$ It is arguable that not all forms of consequentialism are subject to this criticism. This is particularly true of the forms of "justified threat" consequentialism put forward by Farrell (1990) and Ellis (2003).

${ }^{4}$ See, for example, Hanna (2008).

${ }^{5}$ For further details, see Wells (2001), who writes: "From the common law point of view, it is clear that criminal law does address non-human (ie corporate) agents, albeit in a somewhat reluctant and sometimes obscure way" (Wells 2001, 147). As she notes (p. 138), this has traditionally not been true of civil law jurisdictions, although this, too, is changing: for example, in 1991, the French penal code was altered to remove a principle that criminal liability could not attach to "personnes morales." (Jeandidier 1991, 341, cited in Wells 2001, 139).

${ }^{6}$ Thus, for example, in a paper discussing a number of different versions of expressivist justifications of punishment, Nathan Hanna writes: "Of the justifications canvassed here, Duff's is perhaps the most formidable" (Hanna 2008, 142). Cf. Boonin $(2008,172)$.

${ }^{7}$ Duff (2001). Note that the claim is that the communicative function of punishment is essential to the justification of punishment: Duff appears to leave it open that there might be cases of punishment that do not have this function, although such cases of punishment would not be justified (or at least not in the standard way). See Duff (2001, xiv-xv). (I thank an anonymous reader for impressing on me the need to emphasize this point.)

${ }^{8}$ It does not seem to be essential to Duff's view that harsh treatment should be inflicted with the intention of inflicting suffering. For this reason, I believe that Duff's view escapes the objections 
of Hanna (2008). What makes the treatment "harsh" is the fact that it is of a sort that would typically involve hardship on the part of those who are suitably similar to those on whom it is inflicted. See Wringe (forthcoming) for further discussion.

${ }^{9}$ As I argue Wringe (2010).

${ }^{10}$ Duff does not hold that punishment is only acceptable in cases where offenders actually do experience remorse. In fact, it is essential to his view that offenders may reject the communication that is aimed at them: "If it [i.e. punishment] is to consist in a proper attempt to persuade a responsiblemoral agent to repent his crime ... it must leave him free to reject its message" (Duff 2001, 122). Nevertheless, his account does appear to require both that the end aimed at in punishment can be attained and that it be one that has some value. I thank an anonymous referee of the Journal of Social Philosophy for emphasizing the need to be clear on this point.

${ }^{11} \mathrm{My}$ focus here is on corporations. However, there are other kinds of highly structured collective bodies whose susceptibility to punishment might be worth considering, such as states. Many but not all of the points I make here might be taken to apply to them. Matters are much less clear-cut where unstructured collectives are concerned.

${ }^{12}$ Evasive should not be taken in a pejorative sense here: think of the sense of the word in "evasive action," rather than in "evasive politician."

${ }^{13}$ See Wells (2001, chap. 8, and in particular 164-66) for an argument against this third kind of evasive reply.

${ }^{14}$ French (1984) seems to have a view on which corporations are agents, and have beliefs and desires, but not intentions. French $(1996,148-49)$ recants this.

${ }^{15}$ As argued, in a number of different ways by French (1984), Gilbert (1992), and Copp (2006).

${ }^{16}$ As Wells $(2001,8,35)$ notes, in the United Kingdom, at least, many corporate offenses, especially regulatory offenses, are strict liability offenses. In her words, "[r]egulatory schemes have often been adapted to include strict liability offenses as a result of lobbying by the regulatory inspectors" (Wells 2001, 8). Note that regulatory offenses are a part of criminal, not civil, law: in Wells's words, "[a] broad division is often made in criminal law between what are known as regulatory offenses and those which are thought of as conventional crime" (Wells 2001, 2).

${ }^{17}$ One anonymous referee raised the question of whether communicative theorists of punishment, such as Duff, would wish to extend their account to cover strict liability offenses. Duff himself has stated (personal communication) that he thinks that there is no formal inconsistency between the communicative theory and strict liability for criminal offenses, although he does think that there is a question as to whether individuals could be justly punished for such offenses. Duff's own views on strict criminal liability are nuanced: in a later work (Duff 2007, chap. 10), he distinguishes between "strict criminal responsibility" and "strict criminal liability," and also between criminally liability which is "substantially" strict and that which is "formally strict," and argues that there might be a legitimate place for liability that is formally, but not substantively, strict in a system of criminal law. That said, it is worth noting, as Duff himself does, that his discussion covers only individual, and not corporate criminal liability (ibid., footnote 52). However, it seems that it would be, at the very least, hasty to conclude that Duff would rule out the possibility of offenses involving strict liability by collective agents being justifiably punished.

Leaving aside the question of whether regulatory offenses involving strict liability on the part of corporate bodies are properly viewed as part of the criminal law (discussed in footnote 17 above), there seem to be two reasons why one might think that a communicative view would find it difficult to allow for punishment in cases of strict liability. First, one might hold that it is a precondition of the communicative theory that those we punish are responsible agents. Here, we should note that on the view being discussed here — the view of French (1984) — corporate bodies can be responsible agents, even if they do not have intentions: what is required for corporate responsibiulity is that some actions can rightly be attributed to the corporation, and what this requires is not a corporate intention but a corporate decision structure. Second, one might wonder whether it is intelligible to feel remorse for something that one has not intentionally brought about. If not, it might seem that on Duff's communicative account, it would be pointless to address 
punitive communications for such offenses. Duff's position on this seems fairly clear: he holds both that one can feel remorse for states that one has not intentionally brought about—such as being reckless - (and that, therefore, the communicative theory can be extended to cover offenses such as that of reckless driving) and that one can feel remorse for for the results of one's actions which goes beyond remorse for mere intentions (thus, I might feel—and rightly—more remorse for a succesful murder than for an attempt).

${ }^{18}$ Nussbaum $(1996,168 ; 2001,22)$.

${ }^{19}$ See, for example, Roberts (1999, 797-98).

${ }^{20}$ There are some logical bars as to what one can feel remorse for: elsewhere, I have argued that one cannot feel remorse for actions that lie in the future. It may also be logically impossible to feel remorse for actions in cases where one has no connection of any sort with the agent. But in the case under consideration, one does have such a connection. What is in dispute between me and someone who thinks that in these cases remorse is logically impossible is whether the connection is of the right sort.

${ }^{21}$ I am grateful to an anonymous reader for forcing me to clarify the dialectical structure of this paragraph.

${ }^{22}$ Gilbert (2001).

${ }^{23}$ This suggestion is intended as sympathetic exegesis of Gilbert's position. But whether or not it is correct as exegesis, I take it to be a defensible view in its own right.

${ }^{24}$ I take it that in order to defend the application of the communicative view to collective bodies, it needs to be possible to say-as Gilbert does-that the collective body feels remorse, and not simply that it behaves remorsefully, or (as one anonymous reader put it) to act in ways that express a belief on the part of its members that its behavior was defective (although if the collective body feels remorse it will presumably do so in virtue of doing things like this): for further discussion, see the discussion of sincerity in subsequent paragraphs. Notice that this latter, apparently more cautious formulation does not, as one might think, avoids any commitment to a Gilbert-like "plural subject": for the amended acount to be at all plausible, the belief expressed must be some kind of a collective belief, rather than a belief held by each individual member of the collective body.

${ }^{25}$ Thanks to Adam Morton for discussion.

${ }^{26} \mathrm{I}$ am grateful to Christopher Bennett for emphasizing this to me.

${ }^{27}$ This point was suggested to me by Copp (forthcoming). Of course, in the case, Copp is considering that those most directly harmed by the actions in question are long dead and cannot be benefited by expressions of remorse, even though others can. We might hope that not all cases of corporate punishment would involve punishments being inflicted after the death of the victims.

${ }^{28}$ Wells $(2001,5-6,64)$.

${ }^{29}$ Does this point present a problem for the communicative theory as applied to individuals? No, because in the individual case, the communicative theorist does not see the remorse suffered by the criminal in cases of effective punishment as being worthwhile because it benefits the victim of the crime.

${ }^{30}$ Feinberg (1970).

${ }^{31}$ Narayan $(1993,170)$ distinguishes between expressive accounts of punishment that focus on "denunication" and those that focus on "censure." Her distinction between denunciation and censure corresponds to the distinction I am making between denunciatory and communicative theorists. (I talk of "communicative" rather than "censure-based" theories becuase Duff describes his view with the former label.)

${ }^{32}$ But see Fisse and Braithwaite (1993, chap. 6) for a discussion of some relevant considerations from a standpoint that seems consistent with the one put forward here.

${ }^{33}$ The fact that at least some of these goods are not identifiable independently of the practice means that this does not collapse into a consequentialist account (cf. Michael 1992; Duff 2001, 3).

${ }^{34}$ Duff (2001).

${ }^{35}$ Personal communication.

${ }^{36}$ Personal communication. 
${ }^{37}$ Duff $(2001,19)$.

${ }^{38}$ One might argue that by living in a particular territory, individuals consent both to the laws that govern them and the forms of punishment that are typically inflicted on them. If such an account was workable (which I do not think likely), it would be true that the legal punishment of individuals does not involve treating people in ways in which they have not consented to be treated. But such individuals could presumably also be taken to have consented to laws governing corporate misbehavior. So on this account, the denunciatory view is no worse than Duff's communicative account.

${ }^{39}$ A number of authors have argued that we cannot give any justification of punishment as it is currently practiced. See, for example, Golash (2005), Boonin (2008), and Zimmerman (2011). Responding to their arguments falls beyond the scope of this paper.

${ }^{40}$ Duff $(2001,13-14)$.

${ }^{41}$ O’Neill (1989, 110-17). Cf. Korsgaard (1996, 137-40).

${ }^{42}$ There might be some forms of punishment of collective bodies to which this argument could not be applied. One example might be punishing a nation by instituting a boycott that affects all citzens falling into a particular category. What makes the difference in those kinds of cases seems to be that the collective body has little or no way of influencing the way in which the punishment impacts on its members. For further discussion, see Pasternak (2011).

${ }^{43}$ Fisse and Braithwaite (1993, 143-4).

${ }^{44} \mathrm{I}$ have in mind, for example, a situation where, say, a certain set of constitutional arrangements is written into something analogous to French's corporate decision structure, and these arrangements rule out the possibility of the corporation consenting to its own dissolution.

\section{References}

Bennett, Christopher. 2008. The Apology Ritual: A Philosophical Theory of Punishment. Cambridge: Cambridge University Press.

Boonin, David. 2008. The Problem of Punishment. Cambridge: Cambridge University Press.

Copp, David. 2006. "On the Agency of Certain Collective Entities: An Argument from 'Normative Autonomy'." Midwest Studies in Philosophy 30: 194-221.

- 2010. "Corrective Justice as a Duty of the Political Community: David Lyons on the Moral Legacy of Slavery and Jim Crow." Boston University Law Journal 90: 1731-54.

Duff, Antony. 2001. Punishment, Communication and Community. Oxford: Oxford University Press.

- 2007. Answering for Crime: Responsibility and Liability in the Criminal Law. Oxford: Hart Publishing.

Ellis, Anthony. 2003. “A Deterrence Theory of Punishment.” Philosophical Quarterly 53: 337-51.

Farrell, Daniel M. 1990. “The Justification of Deterrent Violence.” Ethics 100: 301-17.

Feinberg, Joel. 1970. "The Expressive Function of Punishment.” In Doing and Deserving, 95-118. Princeton, NJ: Princeton University Press.

Fisse, Owen, and Braithwaite, John. 1993. Corporations, Crime and Accountability. New York: Cambridge University Press.

French, Peter. 1984. Collective and Corporate Responsibility. New York: Columbia University Press. 1996. "Integrity, Intentions and Corporations." American Business Law Journal 34: 141-56.

Gilbert, Margaret. 1992. On Social Facts. Princeton, NJ: Princeton University Press.

- 2001. "Collective Remorse." In War Crimes and Collective Wrongdoing: A Reader, ed. Alexander Jokic, 216-36. Oxford: Blackwell.

Golash, Deirdre. 2005. The Case against Punishment. New York: New York University Press.

Hampton, Jean. 1992. "An Expressive Theory of Retribution." In Retributivism and its Critics, ed. W. Cragg, 1-25. Stuttgart: Franz Steiner.

Hanna, Nathan. 2008. "Say What? A Critique of Expressive Retributivism." Law and Philosophy 27: 123-50. 
Jeandidier, Wolfgang. 1991. Droit pénal des affaires. Paris: Dalloz.

Korsgaard, Christine. 1996. Creating the Kingdom of Ends. Cambridge: Cambridge University Press. Michael, Mark A. 1992. "Utilitarianism and Retributivism: What's the Difference?" American Philosophical Quarterly 29: 173-82.

Narayan, Uma. 1993. "Appropriate Responses and Preventive Benefits: Justifying Censure and Hard Treatment in Legal Punishment.” Oxford Journal of Legal Studies 13: 166-82.

Nussbaum, Martha. 1996. The Therapy of Desire. Princeton, NJ: Princeton University Press. 2001. Upheavals of Thought. Cambridge: Cambridge University Press.

O’Neill, Onora. 1989. Constructions of Reason. Cambridge: Cambridge University Press.

Pasternak, Avia. 2011. "The Distributive Effect of Collective Punishments." In Accountability for Collective Wrongdoing, ed. Tracy Isaacs and Richard Vernon, 210-31. Cambridge: Cambridge University Press.

Roberts, Robert. 1999. "Review: Emotions as Judgments." Philosophy and Phenomenological Research 59: 793-98.

Von Hirsch, Andrew. 1993. Censure and Sanctions. Oxford: Oxford University Press.

Wells, Celia. 2001. Corporations and Criminal Liability, 2nd ed., Oxford: Oxford University Press.

Wringe, Bill. 2010. "War Crimes and Expressive Theories of Punishment: Communication or Denunciation?" Res Publica 16: 119-33.

—. Forthcoming. "Must Punishment Be Intended to Involve Suffering?" Ethical Theory and Moral Practice. doi: 10.1007\%2Fs10677-012-9388-x

Zimmerman, Michael. 2011. The Immorality of Punishment. Buffalo, NY: Broadview Press. 